\title{
A Tribute to Carl C. Bell, MD
}

\author{
Peter Chien ${ }^{1} \mathbb{D}$
}

Received: 30 January 2021 / Accepted: 2 February 2021 / Published online: 8 February 2021

(C) This is a U.S. government work and not under copyright protection in the U.S.; foreign copyright protection may apply 2021

Dr. Carl Compton Bell, a quintessential community psychiatrist, died on August 2, 2019 at age 71. Imagine what a psychiatrist might aspire to do in a lifetime worth of work. Carl did that, and his work is more relevant today than ever. He was an astute clinician, continual educator, clinic CEO, NIMH researcher, prolific writer, leader on national committees, professor and institute director, and a well-recognized mental health advocate. Most critically, he was driven to understand the relatively poor outcomes in mental health care among African-Americans as compared to others and to advocate for corrective systemic changes. He argued for public health approaches to improve mental health, both for the African-American community and for us all.

Being raised in a high achieving family - both his grandfather and father earned PhD's- - he rejected societal notions suggesting that problems within the African-American community arose from their inability to achieve. "His past motivated his work," said his ex-wife, Tyra Taylor-Bell. "He saw friends and classmates who never had a chance to grow up. Then he saw it in schools as an adult. He saw where the problems were, so he did something about it" (Chicago Sun Times 8-3-19). He attended medical school at Meharry Medical College in Tennessee, which taught him scientific rigor and a public health orientation. After residency at the Illinois Psychiatric Institute and psychiatric practice in the Navy, he returned to the South Side of Chicago not far from where he was raised, to work in an African-American community with inadequate resources.

"How do you practice primary prevention in psychiatry?" Carl asked when we met. He looked at me with probing eyes and pursed lips after this difficult first psychiatry residency interview question, trying to elicit an answer. Prevention was a shared interest and I stumbled to connect that with my nascent knowledge of psychiatry. This introduced me

Peter Chien

ptrchien@gmail.com

1 Department of Psychiatry and Behavioral Neurosciences, Loyola University, Chicago, USA to the provoking, profound, uncomfortable, necessary questions which were Carl's modus operandi. After my residency training, I was honored to have the opportunity to work with him at the Community Mental Health Council, the South Side Chicago community mental health clinic, where he was the longtime CEO.

"When opportunities come, you should say yes." he told me. I was a cautious young physician and he encouraged to be professionally involved and use my voice. My first national presentation was on prevention in psychiatry, which I prepared primarily though reading Preventing Mental, Emotional, and Behavioral Disorders Among Young People: Progress and Possibilities, written by the Institute of Medicine committee on which he served. His feedback to me about the presentation was succinct, "You could make money giving that talk around the country."

He called on me to express my opinion when we served together on national committees. He found opportunities for me to write professionally. When I would send him a paper draft late at night, I would have a fully annotated and edited set of comments by the time I woke in the morning. Every time we finished a paper together, he insisted that I put my name ahead of his. Carl was the hardest working person I have ever met and I was honored to have had him as a friend and mentor, as one of the hundreds of fortunate people whom he taught and mentored.

Carl preached the value of the inner life. He knew that his life and work were guided by a deeper force and he performed Tai-Chi every morning before sunrise for expanded consciousness as a gateway to spirituality. This manifested as enduring curiosity, a desire to share and teach, and constant work for change accompanied by the optimism that change was possible.

The Community Mental Health Council abruptly closed in the summer of 2012, amidst financial difficulties in the state and agency. While these difficulties were well-known, word that the agency was closing came suddenly, days before it happened. In case people didn't get the word, he waited in the closed clinic parking lot every day that summer with files in the car, chairs, and a prescription pad to make sure 
people received care and transitioned to other agencies. Carl gave me updates on the many people who arrived this way for their appointments with me and dozens of other staff. He cared for everyone at the clinic, as part of an even broader vision.

"I relied on my predominately African-American clinical population to teach me the truth," he wrote. When he heard patient stories and noticed patterns, he would investigate through epidemiological prevalence studies and case series. He called this "bent-nail research" because he did it without formal grants or funded time. Just like the bookshelf he built as a youth from discarded wood and bent nails, which always held more than its share of books, the research endured and was useful. It often guided and was confirmed by subsequent, more formal research. Later, Carl became a formally-funded National Institute of Mental Health researcher focused on further understanding the principles which strengthen the health of communities. He always brought it back to how it could help people.

Carl was a leading voice on so many issues which affected African-American youth. He elucidated the mental health effects of interpersonal violence, childhood trauma, psychiatric misdiagnosis, overmedication, and systemic discrimination. Always trying to make a difference, he wrote about how to address trauma in the juvenile justice system, stop the correctional pipeline of youth, treat people out of the hospital as outpatients in the community, improve cultural sensitivity and properly diagnose and treat the AfricanAmerican community. He also had a distinct focus on wellbeing strategies including exercise and the martial arts as a way to improve inner states of consciousness. Much of his writing, novel at the time, is accepted in the field as we address trauma-informed care, social determinants of health, racially-equitable care, and the real-world effectiveness of treatment.

He was constantly ahead of his time. As another example, he believed in extending a public health focus to psychiatry before most of field was addressing this. Possibly the most frequent thing he told me was an allegorical story, "If someone comes to the emergency room with a rat bite, you treat them. If another comes, you treat that bite, and then you do something about the rats." He was constantly pushing all who would listen to get rid of rats-to find ways to prevent violence, abuse, poor services, and racial discrimination.

His last dedicated advocacy campaign - to raise awareness, prevent, and treat Fetal Alcohol Exposure-was a culmination of previous themes. Through his clinical work, he often saw a constellation of symptoms-mild intellectual disability, speech, language and learning deficits, attentional difficulties, low frustration tolerance, short-lived emotional outbursts, and poor judgment. The light bulb turned on when he saw this one day in a woman who also had epicanthal folds and characteristic facial features of Fetal Alcohol Exposure. When he began to further look, he found about $40 \%$ of his patients in his South Side Chicago clinic had symptoms consistent with a neurobehavioral disorder due to Fetal Alcohol Exposure, with almost double these rates for patients he treated in the juvenile justice detention center. Additionally, he elicited evidence from most that the mother was drinking alcohol while pregnant, often unintended, before she knew she was pregnant. Most of these patients were misdiagnosed with depression, bipolar disorder, or schizophrenia by other clinicians.

There were clear public health interventions to prevent this. In addition to improving education (of the neighborhood and clinicians), reducing the availability of liquor and liquor stores, and reducing the use of alcohol, an additional public health intervention might be even more feasible. Pre- and post-natal supplementation with a number of vitamins and nutrients, particularly choline, would reduce the effects of Fetal Alcohol Exposure. He authored a study showing that the top prenatal vitamins did not include choline, encouraged further research, and contributed to the American Medical Association passing a resolution calling for choline in prenatal vitamins. This has subsequently happened with some vitamin manufacturers.

For Carl, this brought him full-circle in his advocacy for the African-American community. Through his medical training at Meharry, he learned to address social determinants like poverty, lower education, trauma, and violence which would improve mental health outcomes in the community. As he noticed the underrecognized signs and effects of Fetal Alcohol Exposure in the African-American community, this additionally allowed a preventable biological factor to help people reach their mental health potential.

In his last book, Fetal Alcohol Exposure in the AfricanAmerican Community, he concludes, "The reason I hope you 'get it' is because I am getting old. This may be my last crusade for African-Americans. I have tried to groom my replacements, and I have trained as many as I could to take my place, but some have just not wanted to work as hard as I have worked to dig out information that is real and factual" (p.137).

As I think about all that has happened since his death, I often think about what he would say at this time of heightened mental health stresses and racial reckoning. There is much I would like to ask him about how to better address racial disparities and develop a public mental health response to the stresses experienced since the coronavirus pandemic. While he always had an insight to tell, I imagine he would be quiet, lips pursed, looking probingly, waiting for an answer.

Publisher's Note Springer Nature remains neutral with regard to jurisdictional claims in published maps and institutional affiliations. 